\title{
Aanpak invoering vernieuwingen specialisten- opleiding Kindergeneeskunde en Obstetrie \& Gynaecologie in de OOR Noord- en Oost-Nederland
}

\author{
E. Jippes, L.M. Hercules, E.J. Duiverman, A.A.E. Verhagen, M.J.E. Mourits
}

\begin{abstract}
Samenvatting
Inleiding: De medisch specialistische opleidingen worden op dit moment herzien. De opleidingen Obstetrie \& Gynaecologie en Kindergeneeskunde zijn gestart met de implementatie. In dit artikel worden aan de hand van de aanpak in de noordelijke regio praktische handvatten en inzichten geboden voor het implementeren van een competentiegericht opleidingsplan.
\end{abstract}

Methode: De implementatieaanpak bestaat uit 1) afname van interviews, 2) regionale bijeenkomsten, 3) training van supervisoren en aios in didactische basisprincipes en in het gebruik van de opleidingsinstrumenten, 4) kwaliteitsmetingen van het leerklimaat en van individuele supervisorcompetenties en 5) innovatieprojecten (ontwikkeling van E-portfolio's, modules E-learning, instructie-DVD's en van Elektronische Leer Omgevingen).

Resultaten: de interviews, het hanteren van een projectmatige aanpak, de regionale bijeenkomsten, de gedrevenheid van de artsen, het inschakelen van 'key-figures', het actief betrekken van de artsen en de taakverdeling tussen artsen en ondersteuners zijn positieve punten in het project. Te verbeteren punten in het project zijn een meer intensieve uitwisseling met andere regio's, de structuur en inhoud van de stages, het gebruik van de Elektronische Leer Omgeving en de coaching van supervisoren en aios in het zelf doorvoeren van veranderingen.

Discussie/conclusie: De opleidingsvernieuwingen komen voort uit een nieuwe visie en filosofie op opleiden. Het succes van implementatie hangt voor een belangrijk deel af van het feit of supervisoren en artsen in opleiding tot specialist (aios) deze nieuwe manier van opleiden omarmen en van daaruit elkaar inspireren. Daar ligt de grootste uitdaging. (Jippes E, Hercules LM, Duiverman EJ, Verhagen AAE, Mourits MJE. Aanpak invoering vernieuwingen specialistenopleiding Kindergeneeskunde en Obstetrie \& Gynaecologie in de OOR Noord-en Oost-Nederland. Tijdschrift voor Medisch Onderwijs 2008;27(4):181-190.)

\section{Inleiding}

In de landelijke dagbladen en tijdschriften verschijnen steeds vaker artikelen waarin niet zozeer de kwaliteit van de medische zorg, maar vooral aspecten als communicatie, organisatie, samenwerking en reflectie het onderwerp zijn. ${ }^{1-4}$ Patiënten verlangen van medisch specialisten kwalitatief hoogstaande zorg op al deze gebieden. Deze maatschappelijke factoren vormen een belangrijke aanleiding voor grote veranderingen in de medisch specialistische opleidingen in Nederland. De opleidingen worden competentiegericht ingericht, zodat in navolging van de introductie van de CanMEDS-rollen in Canada, ${ }^{5}$ ook in Nederland medisch specialisten expliciet en aantoonbaar opgeleid worden binnen zeven competentiegebieden: medisch handelen, communicatie, samenwerking, kennis en wetenschap, organisatie, maatschappelijk handelen en 
professionaliteit. ${ }^{6}$ Artsen in opleiding tot specialist (aios) worden in de vernieuwde opleidingen via een systeem van toetsing en kwaliteitszorg volgens de zeven competentiegebieden opgeleid. Hierdoor leert de aios explicieter en krijgen de opleider en de opleidingsgroep meer grip en sturingsmogelijkheden. De Korte Praktijk Beoordelingen (KPB's), het portfolio en de voortgangsgesprekken maken onderdeel uit van dit systeem. ${ }^{7}$

Wetenschappelijke verenigingen zijn op dit moment bezig met het uitwerken van de opleidingsplannen volgens de nieuwe richtlijnen. De opleidingen Kindergeneeskunde (KG) en Obstetrie \& Gynaecologie $(O \& G)$ hebben hun opleidingsplannen als eerste gereed. Het vernieuwde opleidingsplan van Kindergeneeskunde heet Generieke Onderwijs en Evaluatie Doelen (GOED) en van Obstetrie \& Gynaecologie heet Herziening Opleiding Obstetrie \& Gynaecologie (HOOG).

\section{Het In VIVO-project}

In oktober 2006 is het project 'Vaart in Innovatie VervolgOpleidingen' (In VIVO) gestart met als eerste doelstelling de implementatie van de vernieuwde opleidingen van $K G$ en $O \& G$ in alle acht Onderwijs en OpleidingsRegio's (OOR's). Het College voor Beroepen en Opleidingen in de Gezondheidszorg (CBOG) is eigenaar van het project. Het project wordt aangestuurd door een landelijk projectteam dat zich bezighoudt met het faciliteren en coördineren van richtlijnen die in de OOR's ontwikkeld worden en met het vormgeven en uitvoeren van het evaluatieonderzoek.

Belangrijk in dit project is het inzichtelijk maken van de in het implementatieproces opgedane ervaringen en vastgestelde verbeterpunten en deze te delen met de andere medisch specialistische opleidingen van Nederland. ${ }^{8}$ Met dit uit- gangspunt in het achterhoofd doen wij in dit artikel verslag van de aanpak van het In VIVO-project in de OOR Noord- en Oost-Nederland (OOR NO) en van de successen en valkuilen die zich daarbij voordoen. Met deze inzichten kunnen andere kernteams van In VIVO, en andere medisch specialistische opleidingen die hun opleidingsplannen gaan implementeren, hun voordeel doen.

$\mathrm{Na}$ algemene informatie over het In VIVO-project worden de verschillende activiteiten in het In VIVO-project in de OOR NO besproken. Tot slot geven we aan wat goed gaat, wat beter kan en welke adviezen we kunnen formuleren.

\section{Doelstellingen}

Het doel van dit project is het opdoen van ervaring met het implementeren van de vernieuwde opleidingsplannen voor de opleidingen O\&G en KG door middel van: ${ }^{8}$

- ontwikkelde en beproefde onderwijsmaterialen (portfolio's, KPB's)

- de opbouw van een onderwijskundige infrastructuur in de OOR's

- inzicht in benodigde tijdsinvestering

- bevorderende en belemmerende factoren voor implementatie

- evaluatieonderzoek naar de effectiviteit en doelmatigheid van de vernieuwingen.

\section{Regionale Kernteams}

In iedere OOR zijn kernteams benoemd, waarin tenminste twee kinderartsen, twee gynaecologen, vier aios en een onderwijskundige zitting hebben. De kernteams vervullen een spilfunctie voor de implementatie in de ziekenhuizen ter plaatse en hebben de volgende taken:

- Communiceren: verspreiden van informatie vanuit de landelijke projectgroep en andere OOR's naar opleiders, opleidingsgroepen en aios en vice versa. 
- Trainen: organiseren van docenttrainingen en 'coaching on the job'.

- Faciliteren: verspreiden van materialen en informatie over successen en valkuilen aan opleiders, opleidingsgroepen en aios en de vaart erin houden!

- Evalueren: ondersteunen en uitvoeren van het evaluatieonderzoek.

\section{Methode en resultaten}

\section{Literatuurverkenning}

Uit onderzoek blijkt dat innovatie- en veranderprocessen dynamisch en contextspecifiek zijn en dat het succes van adoptie en implementatie van veranderingen veelal van meerdere factoren in de specifieke context afhankelijk is. ${ }^{9}$ Dit dynamische karakter werd bevestigd in een studie naar de implementatie van opleidingsvernieuwingen in het Beatrix Kinderziekenhuis te Groningen. ${ }^{10}$ Daaruit blijkt dat bij het implementatieproces van deelprojecten er een sterke variatie is in snelheid en succes.

\section{Interviews met opleiders en aios}

Het implementatieproces in de OOR NO is in december 2006 gestart met het houden van interviews met opleiders en aios uit de deelnemende ziekenhuizen. Deelnemende ziekenhuizen zijn het Universitair Medisch Centrum Groningen, Martini Ziekenhuis, Deventer Ziekenhuis, Medisch Spectrum Twente, Isala klinieken Zwolle en het Medisch Centrum Leeuwarden. In de interviews werd de vraag gesteld wat volgens opleiders en aios nodig is om de vernieuwingen te implementeren.

\section{Projectmatige aanpak}

In de OOR NO wordt In VIVO op een projectmatige manier aangepakt. Projectmatig werken verschaft helderheid over de te behalen doelen, de resultaten, de rollen van de diverse betrokkenen en over de benodigde middelen, tijd en geld. ${ }^{11}$

In tabel 1 is een overzicht weergegeven van de ideeën die zijn genoemd in de interviews en de projecten die op basis hiervan zijn gestart.

Tabel 1. Ideeën die zijn genoemd in de interviews, gekoppeld aan de deelprojecten.

\begin{tabular}{ll}
\hline Genoemde ideeën & Opgestarte deelprojecten \\
\hline $\begin{array}{l}\text { Goede informatievoorziening in de OOR voor het } \\
\text { uitwisselen van kennis en ervaringen }\end{array}$ & $\begin{array}{l}\text { Hoofdproject Organisatie van halfjaarlijkse regionale } \\
\text { bijeenkomsten }\end{array}$ \\
& Project Elektronische leeromgeving \\
$\begin{array}{l}\text { Trainen van specialisten en aios in didactische basis- } \\
\text { principes en het gebruik van de opleidingsinstrumenten }\end{array}$ & - Project Aios-lunches \\
$\begin{array}{l}\text { Meten van het gebruik van de opleidingsinstrumenten } \\
\text { in de opleidingsklinieken }\end{array}$ & - Project Onderzoek \& Kwaliteitszorg \\
$\begin{array}{l}\text { Digitaliseren van opleidingsinstrumenten, } \\
\text { met name het portfolio }\end{array}$ & - Project Digitaal Portfolio \\
$\begin{array}{l}\text { Visualiseren van het gebruik van opleidingsinstrumenten, } \\
\text { bijvoorbeeld de afname van de KPB } \\
\text { Opzetten modules bestaande uit E-learning, skillstrainingen } \\
\text { en opdrachten op de werkplek } \\
\text { Hulp bij het inroosteren van aios en specialisten voor de } \\
\text { afname van de KPB }\end{array}$ & - Project Introductievideo's \\
\hline
\end{tabular}




\section{Taakverdeling artsen en ondersteuners}

De taken tussen artsen en ondersteuners zijn zo verdeeld dat artsen zelf het boegbeeld van de vernieuwingen zijn en bijvoorbeeld zelf bijeenkomsten leiden, presentaties verzorgen en voorlichting geven aan hun collegae. De ondersteuners (onderwijskundigen en bedrijfskundigen) geven hen handvatten om de vernieuwingen zo goed mogelijk te implementeren. $\mathrm{Zij}$ bereiden presentaties voor, organiseren bijeenkomsten, ontwikkelen een gids met een aanbod voor docent- en aios-professionalisering, maken een elektronische leeromgeving, etc. De artsen en onder- steuners stippelen gezamenlijk beleid uit ten aanzien van alle projecten. Een dergelijke duidelijke taakverdeling is bevorderlijk volgens Huberman. ${ }^{12}$ Hij wijst erop dat bij het invoeren van veranderingen taken in onderwijs en opleiding slim moeten worden verdeeld tussen de lerende professional zelf en de mensen met een ondersteunende en begeleidende rol.

In tabel 2 staat bij ieder project een omschrijving van de projectdoelen, de concrete aanpak, de taakverdeling tussen artsen en ondersteuners en de resultaten tot nu toe. Voor ieder project is een projectplan geschreven en beschikbaar.

Tabel 2. Projecten In VIVO OOR NO.

\begin{tabular}{|c|c|}
\hline \multicolumn{2}{|c|}{ Hoofdproject: organisatie van regionale bijeenkomsten } \\
\hline Projectdoelen & $\begin{array}{l}\text { - Enthousiasmeren en uitwisselen van ervaringen, ideeën en producten } \\
\text { - Doelen stellen en evalueren of de doelen behaald zijn }\end{array}$ \\
\hline Concrete aanpak & $\begin{array}{l}\text { - Organisatie van halfjaarlijkse bijeenkomsten voor alle opleiders, supervisoren en aios KG } \\
\text { en O\&G in de OOR NO. Hierbij worden tenminste de opleider, } 1 \text { staflid en } 1 \text { aios van ieder } \\
\text { ziekenhuis en specialisme verwacht } \\
\text { - De bijeenkomst duurt een middag en bestaat uit een uitwisselingsgedeelte en een trai- } \\
\text { ningsgedeelte/workshops }\end{array}$ \\
\hline Taken artsen & $\begin{array}{l}\text { - Inhoudelijk vormgeven van de bijeenkomsten } \\
\text { - } \quad \text { Voorzitten van de bijeenkomsten } \\
\text { - Overtuigen en enthousiasmeren van collegae van nut en noodzaak van de vernieuwingen }\end{array}$ \\
\hline Taken ondersteuners en anderen & $\begin{array}{l}\text { - Onderwijskundig vormgeven, plannen en organiseren van de bijeenkomsten } \\
\text { - Presentaties voorbereiden }\end{array}$ \\
\hline Resultaten tot nu toe & $\begin{array}{l}\text { - Drie regionale bijeenkomsten georganiseerd, januari 2007, juni } 2007.18 \text { januari } 2008,4^{\text {de }} \\
\text { gepland op } 20 \text { juni } 2008 \\
\text { - Deze bijeenkomsten werden goed bezocht en werden goed geëvalueerd door de deelnemers } \\
\text { - } \quad \text { Van de bijeenkomst op } 18 \text { januari is evaluatiedata beschikbaar: } \\
\text { - } \quad \text { Er waren } 46 \text { deelnemers, waaronder } 16 \text { (plv.)opleiders, } 6 \text { supervisoren, } 16 \text { aios, } \\
2 \text { landelijke vertegenwoordigers van In-VIVO en } 6 \text { mensen voor ondersteuning } \\
\text { - } 17 \text { (pl.) opleiders, supervisoren en aios beantwoordden } 10 \text { stellingen (t.a.v. de doelen } \\
\text { van de middag) op een 5-punts schaal. De gemiddelde score op de stellingen is 3,95 }\end{array}$ \\
\hline & Project docentprofessionalisering \\
\hline Projectdoelen & $\begin{array}{l}\text { - Supervisoren en aios trainen in het geven van gestructureerde en veilige feedback volgens de } \\
\text { competenties en het gebruik van de opleidingsinstrumenten KPB, OSATS en het portfolio } \\
\text { - Enthousiasmeren }\end{array}$ \\
\hline Concrete aanpak & $\begin{array}{l}\text { - Gids docent- en aios-professionalisering gemaakt met het volgende aanbod: } \\
\text { 1. (2 daagse) Cursus Teach the Teacher } 1 \text { Didactische Basisprincipes toegesneden op In } \\
\text { VIVO }\end{array}$ \\
\hline
\end{tabular}




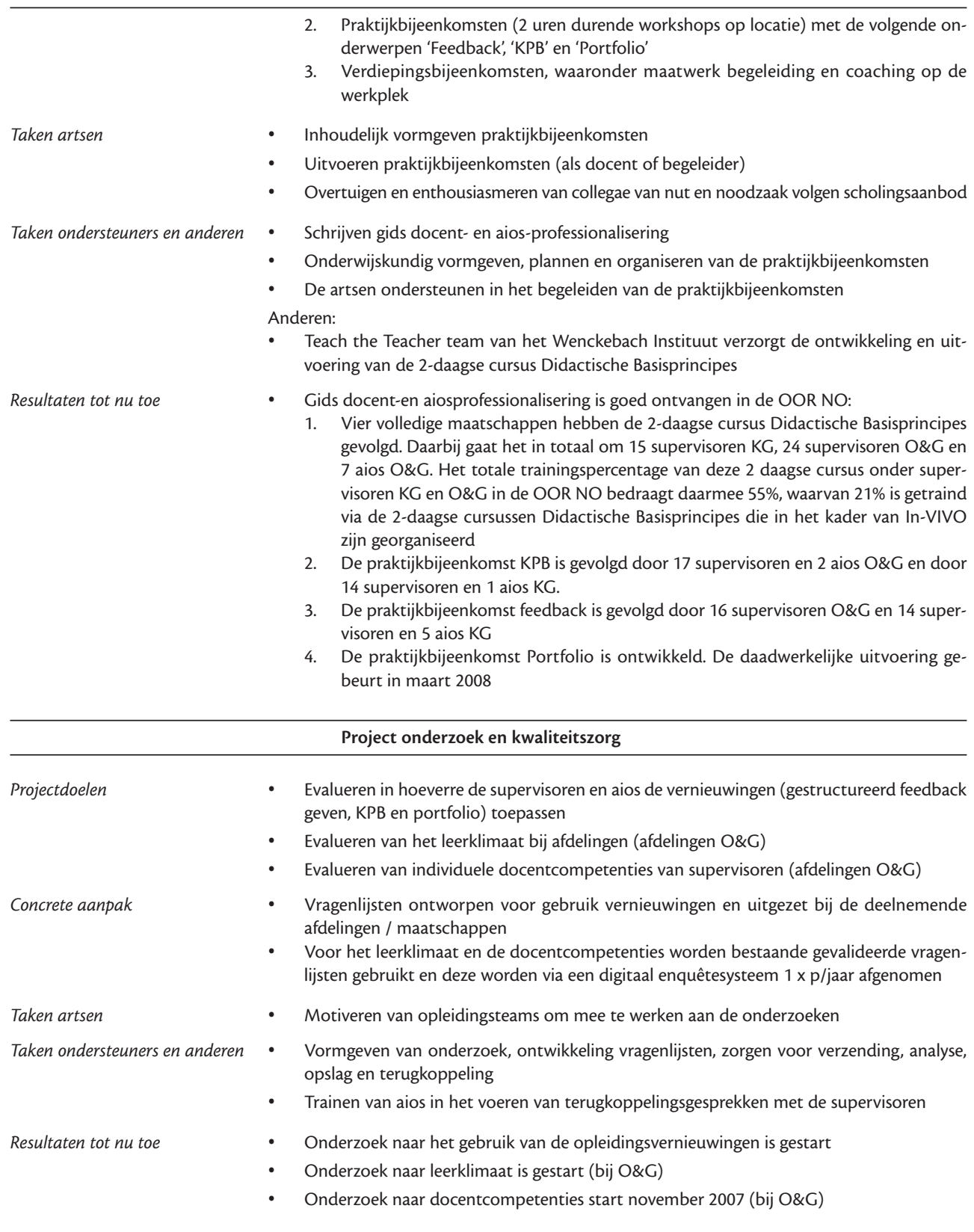

Project digitaal portfolio

Projectdoelen

Concrete aanpak
- Digitaliseren papieren portfolio om het gebruik door de stakeholders te bevorderen;

- Verbeteren papieren portfolio

- Expertisegroep is geformeerd bestaande uit gynaecologen, kinderartsen, aios, onderwijskundige en ICT expert 
Vernieuwing opleiding KG en O\&G in OOR NO $\mid$ E. Jippes et al.

\begin{tabular}{|c|c|}
\hline Taken artsen & - Zorgen voor inhoudelijke vormgeving en het testen van het portfolio \\
\hline \multirow[t]{3}{*}{ Taken ondersteuners en anderen } & - Onderwijskundige vormgeving portfolio en begeleiden van proces \\
\hline & Technische ondersteuners: \\
\hline & - Ontwerpen, testen en invoeren digitaal portfolio in bestaande leeromgeving \\
\hline \multirow[t]{2}{*}{ Resultaten tot nu toe } & - Pilot portfolio is gereed, maar nog niet getest door gebruikers \\
\hline & Project introductievideo's \\
\hline Projectdoelen & - Bevorderen van het gebruik van de opleidingsinstrumenten \\
\hline \multirow[t]{4}{*}{ Concrete aanpak } & - Vaststellen onderwerp eerste video \\
\hline & - Schrijven draaiboek met rolverdeling specialisten en aios \\
\hline & - Benaderen acteurs (specialisten en aios) \\
\hline & - Opnemen en bewerken videomateriaal, inclusief voice-overs \\
\hline \multirow[t]{2}{*}{ Taken artsen } & - Meedenken over inhoud van video \\
\hline & - Als acteur meedoen in video \\
\hline \multirow[t]{2}{*}{ Taken ondersteuners en anderen } & $\begin{array}{l}\text { - Procesbegeleiding, contacten leggen, script en voice-overs schrijven, onderwijskundige } \\
\text { vormgeving en uitvoering DVD }\end{array}$ \\
\hline & $\begin{array}{l}\text { Anderen: } \\
\text { - Multimediateam van het Wenckebach Instituut voor video-opnames, technische vorm- } \\
\text { geving en uitvoering }\end{array}$ \\
\hline Resultaten tot nu toe & $\begin{array}{l}\text { - Eerste DVD KPB geproduceerd, verspreid in de regio en hierover zijn positieve reacties } \\
\text { ontvangen }\end{array}$ \\
\hline
\end{tabular}

Project E-learning, skillslab en cursorisch onderwijs

Projectdoelen

Concrete aanpak

Taken artsen

Taken ondersteuners en anderen

Resultaten tot nu toe
- Ontwikkeling E-learning modules die ingebed zijn in de opleiding van aios

- Vormgeven gestructureerde stages waarin werkplekleren, cursorisch onderwijs en skills-labtrainingen goed op elkaar aansluiten.

- Groep geformeerd voor het ontwikkelen van een E-learningmodule rondom het onderwerp "nekplooimeting en counseling" O\&G

- Stagehandleidingen maken waarin (o.a.) de E-learningmodule een duidelijke plek heeft

- Inhoudelijke vormgeving E-learningmodule

- Competenties uit opleidingsplan 'verdelen' over verschillende stages

- Meedenken over inhouden stagehandleiding

- Procesbegeleiding, onderwijskundige en technische vormgeving E-learningmodule.

- Onderwijskundige ondersteuning bij structureren stage en schrijven stagehandleiding

- Gestart met de ontwikkeling E-learningmodule 'nekplooimeting en counseling bij zwangeren'

- Nog niet gestart met structureren van stages.
Projectdoelen

Concrete aanpak

Project elektronische LeerOmgeving (ELO)

- Uitwisselen van kennis en ervaringen rondom opleidingsvernieuwingen

- Enthousiasmeren van supervisoren en aios voor opleidingsvernieuwingen

- Elektronische leeromgeving (ELO) in blackboard aangemaakt

- Structuur opgezet waarin ruimte is voor plaatsen informatie, discussie via forum, plaatsen opleidingsinstrumenten en planningen, presentaties en ander materiaal voor cursorisch onderwijs 
Vernieuwing opleiding KG en O\&G in OOR NO $\mid$ E. Jippes et al.

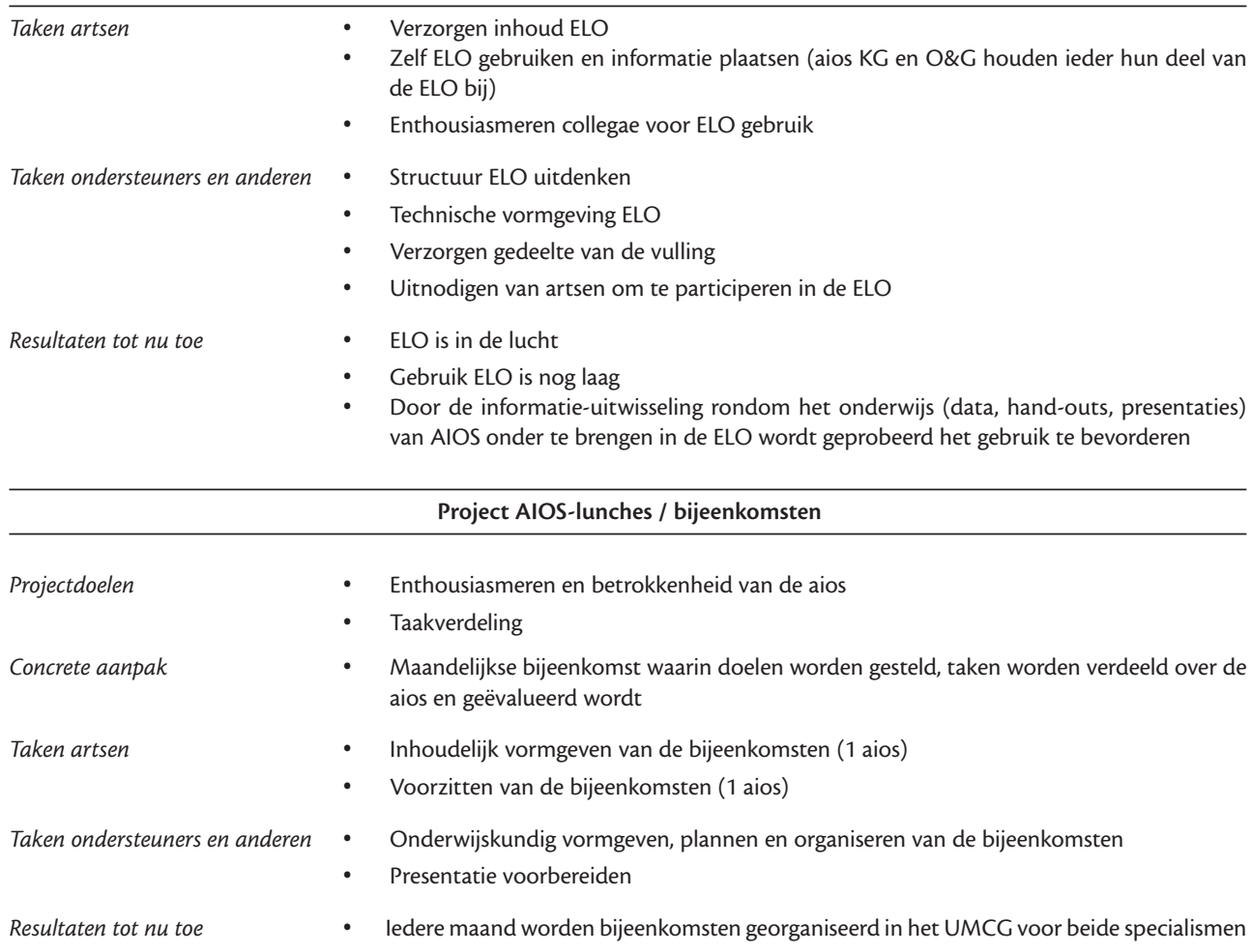

\section{Discussie}

Uit de ervaringen in de OOR NO tot nu toe kunnen we aangeven waar we tevreden over zijn, wat beter kan en tot slot wat we anderen zouden adviseren.

\section{Waar zijn we tevreden over?}

We zijn tevreden over:

- De start met de interviews met de betrokkenen. Dit genereert ideeën welke de basis vormen voor de op te starten projecten en het zorgt voor draagvlak.

- Het formuleren van (deel)resultaten en een plan van aanpak volgens de methode van projectmatig werken. Hierdoor wordt gestructureerd naar resultaten toe gewerkt en worden rollen en taken helder verdeeld.

- De regionale bijeenkomsten. Deze bijeenkomsten zorgen voor enthousiasme en uitwisseling van ervaringen en producten en bieden de opleidingsgroepen steun bij het stellen van doelen voor zichzelf en het committeren daaraan.

- De aios-lunches. Hier wordt betrokkenheid onder aios gegenereerd en het is een plek om ervaringen uit te wisselen en taken te verdelen.

- Het inschakelen van 'key-figures'; opleiders, supervisoren en aios die de nieuwe manier van opleiden goed over het voetlicht kunnen brengen onder hun collegae.

- Het actief betrekken van opleiders, supervisoren en aios in deelprojecten waardoor ze invloed kunnen uitoefenen op de ontwikkeling van een project en hier verantwoordelijkheid voor voelen.

- De uitstekende samenwerking tussen artsen en ondersteuners en een duidelijke taakverdeling tussen hen. Dit zorgt 
voor een efficiënte manier van werken. De vaart kan zo letterlijk in het vernieuwingsproject worden gehouden.

- Het ontwikkelen van het digitaal portfolio parallel aan het gebruik van het papieren portfolio in de praktijk. Het ontwikkelen van het digitaal portfolio zorgt ervoor dat er zorgvuldig nagedacht moet worden over de wijze waarop dit portfolio in de onderwijspraktijk gebruikt moet worden. De ervaring in de onderwijspraktijk wordt opgedaan met het gebruik van het papieren portfolio. Deze beide processen hebben een positieve invloed op elkaar.

\section{Wat kan beter?}

We vinden dat de volgende punten beter kunnen:

- Het uitwisselen van ervaringen met de andere OOR's.

- Het besteden van aandacht aan de structuur en inhoud van de stages en de begeleiding daaromheen.

- Het bij elkaar brengen van mensen, expertise en middelen voor de uitvoering van deelprojecten.

- Het gebruik van de Elektronische LeerOmgeving voor de opleidingsvernieuwingen.

- De coaching van aios, supervisoren en opleiders in het zelf doorvoeren van verandertrajecten.

\section{Conclusie}

Zoals uit de literatuurverkenning blijkt zijn innovatie- en veranderprocessen per definitie complex, dynamisch en contextspecifiek en is het succes van een veelheid van factoren afhankelijk. In de projectopzet en -aanpak van In VIVO in de OOR NO is hiermee rekening gehouden. Opleidingsklinieken zijn vrij om eigen vernieuwingen door te voeren. De regionale bijeenkomsten vervullen een stimulerende rol in het formuleren van doelen en evalu- eren van activiteiten en hebben als doel voldoende dynamiek en draagvlak in opleidingsgroepen te creëren voor de veranderingen. Een standaard recept voor het invoeren van vernieuwingen is dus niet te geven. In dit artikel is verslag gedaan van een aanpak die in de OOR NO resultaten oplevert. Betrokkenen (opleiders, supervisoren, aios, ondersteuners) kunnen hier elementen uithalen en inzetten in hun eigen context.

De opleidingsvernieuwingen bestaan voor een deel uit de invoering van een serie instrumenten (KPB's, 360 graden beoordelingen, bekwaamheidsverklaringen, portfolio's, etc.). De invoering hiervan is zichtbaar en het meest aantrekkelijk om bij het innovatieproces de energie en aandacht op te richten. Echter, achter deze instrumenten zit een bepaalde filosofie over opleiden. Het opleidingsproces dient gestructureerd te verlopen, het moet gericht zijn op het verwerven van competenties. Voorts dient expliciet geobserveerd en getoetst te worden of de aios deze competenties beheerst en of de aios op een gestructureerde manier feedback ontvangt en gecoacht wordt in het opleidingsproces. Dit betekent dat naast de adoptie van de instrumenten het misschien nog wel het belangrijkste is dat de professionals deze filosofie adopteren. Daar er sprake is van opgelegde veranderingen is dit geen sinecure.

In de 'omarming' van de nieuwe opleidingsfilosofie schuilt de grootste uitdaging. Met het inschakelen van 'key-figures' uit het eigen werkveld en het voorbeeldgedrag van deze personen, met maatwerktrainingen, met het actief betrekken van supervisoren en aios in de ontwikkeling (zodat het aan hun wensen voldoet) en bovenal met veel communicatie wordt geprobeerd dit voor elkaar te krijgen in het In VIVO-project. Dit is een (langdurig) proces dat met goed doordachte acties en 
interventies op den duur zijn vruchten af zal werpen.

\section{Dankwoord}

Voor het kritisch bekijken van het artikel willen wij Jan Pols bedanken. Ook willen we alle leden van het kernteam van de OOR NO, de opleiders en aios O\&G en KG bedanken voor hun inzet in het project.

\section{Literatuur}

1. Steenhorst R. Blunders arts. Aio's aan lot overgelaten. De Telegraaf 2007. [Blundering doctors. Trainees left unsupervised. The Telegraph 2007].

2. Externe OnderzoeksCommissie o.l.v.Vesseur (Inspectie voor de Gezondheidszorg). Een tekortschietend zorgproces. Een onderzoek naar de kwaliteit en veiligheid van de cardiochirurgische zorgketen voor volwassenen in het UMC St Radboud te Nijmegen. Interne notitie. Inspectie voor de Gezondheidszorg 2006. [External Investigative Committee chaired by Vesseur (Health Care Inspectorate). Shortcomings in the health care process. An investigation into the quality and safety of cardiac surgical care for adults in UMC St Radboud, Nijmegen, the Netherlands. Internal memorandum. Health Care Inspectorate 2006].

3. Diemen-Steenvoorde R. Artsen moeten meer rollen leren. Med Contact 2006;13:519-20. [Doctors have to take on new roles. Medical Contact 2006;13:519-20].

4. Pronk. Het recept voor ruzie: medisch specialisten werken in een emotioneel mijnenveld. Med Contact 2006 [A recipe for conflict: medical specialists are working in an emotional minefield. Medical Contact 2006].

5. Rourke J, Frank JR. Implementing the CanMEDSTM physician roles in rural specialist education: the Multi-Specialty Community Training Network. Rural And Remote Health 2005;5(4):406.

6. Bleker OP, Hoorntje JCA, Schelfhout VJ. Beter en leuker. CCMS ontvouwt plannen voor de vervolgopleiding van medisch specialisten. Medisch Contact 2004:59(43):1692-5. [More effective and more exciting. CCMS presents plans for postgraduate specialist training. Medical Contact 2004;59(43):1692-5].

7. Centraal College Medisch Specialisten. Kaderbesluit CCMS 9 februari 2004. Staatscourant 2004, Dec 14; 241. [Central College of Medical Specialties. CCMS Framework Decision, February 2004. Bulletin of Acts, Orders and Decrees 2004, Dec 14; 241].
8. Implementatiepilot In-VIVO start 17 oktober 2006. 2006 (Implementation pilot of In-VIVO starts 17 October 2006) http://www.medischevervolgopleidingen.nl/pages/content/S2/nieuws29.aspx. [visited 10-6-08]

9. Greenhalgh T, Robert G, MacFarlane F, Bate P, Kyriakidou O. Diffusion of innovations in service organizations: systematic review and recommendations. The Milbank Quarterly 2004;82(4):581-629.

10. Pols J, Jippes E, Verhagen AEE, Hercules LM, Sauer PJJ. Vernieuwing opleiding kindergeneeskunde in de Beatrix Kinderkliniek, Universitair Medisch Centrum Groningen. Tijdschrift voor Medisch Onderwijs 2007;26(2):63-74. [Innovation in postgraduate training in paediatrics in Beatrix Children's Clinic, University Medical Center Groningen, Dutch Journal of Medical Education 2007;26(2):63-74.

11. Bos J, Harting E. Projectmatig creëren. Schiedam: Scriptum; 2006. [Creating in projects. Schiedam: Scriptum; 2006].

12. Huberman M. Networks that alter teaching, conceptualizations, exchanges and experiments. Teaching and Teachers 1995;(1):193-212.

De auteurs:

Drs. E. Jippes is bedrijfskundige, Wenckebach Instituut. Mw. drs. L.M. Hercules is onderwijskundige, Wenckebach Instituut.

Prof. dr. E.J. Duiverman is kinderarts en plv. opleider, Beatrix Kinderziekenhuis.

Mr. drs. A.A.E. Verhagen is kinderarts en chef de clinique, Beatrix Kinderziekenhuis.

Mw. prof. dr. M.J.E. Mourits is gynaecoloog en opleider, Obstetrie \& Gynaecologie

Allen zijn verbonden aan het Universitair Medisch Centrum Groningen.

Correspondentieadres:

Drs. E. Jippes, Wenckebach Instituut, UMCG, Postbus 30.001, 9700 RB Groningen, De Brug 5.040. Tel.: 050-3619702; e-mail: e.jippes@wenckebach.umcg.nl | www.wenckebachinstituut.nl

Belangenconflict: geen gemeld.

Financiële ondersteuning: geen gemeld. 


\author{
Vernieuwing opleiding KG en O\&G in OOR NO $\mid$ E. Jippes et al.
}

\title{
Summary
}

Introduction: Postgraduate specialist training in the Netherlands is undergoing structural reform. Currently, new training programmes in Obstetrics and Gynaecology and in Paediatrics are being implemented. In this article we present practical suggestions and insights based on experiences with the introduction of competence-based specialist training in the northern region of the Netherlands.

Method: The implementation strategy comprises: (1) interviews (2) regional meetings (3) training of supervisors and trainees in didactic principles and the use of training methods (4) evaluation of the quality of the educational climate and individual supervisors' teaching skills and (5) innovative projects (the development of e-portfolios, e-learning modules, instruction DVDs and an electronic learning environment).

Results: The strengths of this approach are: the interviews, the projects, the regional meetings, doctors' enthusiasm, the involvement of key players, the active involvement of doctors in the projects, and collaboration between doctors and educationalists. Improvement is needed in the following aspects: more intensive exchange of knowledge with other regions, the structure and content of training periods, the use of the electronic learning environment, and coaching to help program directors, supervisors, and residents in introducing the changes.

Discussion/conclusion: The current changes in postgraduate training programmes are inspired by new educational ideas and concepts. The successful introduction of the new programmes depends largely on whether supervisors and trainees will embrace the new educational approach and support each other in implementing the changes. The main challenge lies in fostering this positive attitude in teachers and trainees. (Jippes E, Hercules LM, Duiverman EJ, Verhagen AAE, Mourits MJE. An approach to introducing changes in postgraduate specialist training in paediatrics and obstetrics and gynaedology: experiences from the northern region of the Netherlands. Dutch Journal of Medical Education 2008;27(4):181-190.) 